\title{
PENGARUH LAMA WAKTU FERMENTASI TERHADAP KADAR BIOETANOL DARI PATI UBI JALAR KUNING (Ipomea batata L)
}

\section{The Influence of A Long Time Fermentation Againts bioethanol levels of Starch Sweet Potato is Yellow (Ipomea batatas L)}

\author{
*Fika Herlina Moede, Siang Tandi Gonggo, dan Ratman
}

Pendidikan Kimia/FKIP - Universitas Tadulako, Palu - Indonesia 94118

Recieved 06 March 2017, Revised 05 April 2017, Accepted 05 May 2017

\begin{abstract}
The sweet potato is yellow is one that the carbohydrate that is high, so it can be used as one of the alternative raw materials for bioetanol. This study aims to determine the levels of ethanol sweet potato is yellow through fermentation with the use of yeast bread with a variety of time 3, 4, 5, 6, dan 7 days at room temperature. The results of research shows glucose levels derived from the process of hydrolysis using acid $\mathrm{HCl} 21 \%$ are of $4,54 \%$ with high levels ethanol that optimum obntained through fermentation use of yeast Saccharomyces cerevisiae of 9,70\% over fermentation 5 days.
\end{abstract}

Keywords: Bioethanol, sweet potato is yellow, hidrolisis, fermentation

\section{Pendahuluan}

Cadangan minyak bumi yang semakin menipis seiring dengan meningkatnya jumlah konsumen menyebabkan melonjaknya harga BBM dan krisis energi. Oleh karena itu semakin banyak dikembangkan berbagai sumber energi alternatif seperti energi matahari, energi air, energi panas bumi, dan berbagai sumber energi lainnya. Dasar pemilihan sumber energi yang akan dimanfaatkan antara lain terbarukan dan ramah lingkungan. Salah satunya adalah bioetanol (Rikana \& Adam, 2008).

Bioetanol merupakan etanol yang diproduksi dari tumbuh-tumbuhan menggunakan mikroorganisme melalui proses fermentasi. Mikroorganisme yang paling banyak digunakan dalam fermentasi alkohol adalah Saccharomyces cerevisiae (ragi roti) karena harganya murah dan lebih mudah didapat (Kartika, dkk., 1992). Bahan baku bioetanol dapat berasal dari biomassa sumber pati (jagung, ubi kayu, sorgun, dan lain-lain), sumber gula (molasses, nira tebu, nira kelapa, dan nira dari berbagai tanaman lain), dan sumber selulosa (onggok, jerami padi, ampas tebu, tongkol jagung, dan lain-lain sebagainya (Mulyono, dkk., 2011).

*Correspondence:

Fika Herlina Moede

Program Studi Pendidikan Kimia, Fakultas Keguruan dan Ilmu Pendidikan, Universitas Tadulako

email: fikaherlina05@gmail.com

Published by Universitas Tadulako 2017
Ubi jalar merupakan komoditas sumber karbohidrat utama, setelah padi, jagung, dan ubi kayu, serta mempunyai peranan penting dalam penyediaan bahan pangan, bahan baku industri maupun pakan ternak (Zuraida \& Supriati, 2001). Bagian tanaman ubi jalar yang dapat digunakan sebagai bahan bakar alternatif adalah umbinya karena banyak mengandung pati atau karbohidrat sebesar $27,9 \%$ per 100 gram berat bahan. Hal ini memungkinkan untuk dapat digunakan sebagai bahan baku industri berbasis pati dan sebagai salah satu alternatif untuk bahan baku pembuatan etanol (Damardjati \& Widowati, 1994).

Etanol adalah alkohol yang didapat dari fermentasi bahan-bahan yang mengandung gula, pati atau selulosa. Etanol merupakan bahan yang sangat penting karena merupakan bahan bakar cair dari sumber yang dapat diperbaharui (bioetanol). Bioetanol merupakan bahan bakar oksigenat yang mengandung 35\% oksigen yang dapat mereduksi partikulat dan emisi NOx dari hasil pembakaran (Demirbas, 2005).

Bioetanol dapat digunakan sebagai pengganti BBM tergantung dari tingkat kemurniannya. Bioetanol dengan kadar 95-99\% dapat dipakai sebagai bahan substitusi premium (bensin), sedangkan kadar 40\% dipakai sebagai bahan substitusi minyak tanah (Rahmawati, 2010).

Hidrolisis dapat menggunakan beberapa 
metode diantaranya yaitu metode kimia (hidrolisis asam) dan metode enzimatis (hidrolisis enzim). Metode kimiawi dilakukan dengan cara hidrolisis pati menggunakan asamasam organik, yang sering digunakan adalah $\mathrm{H}_{2} \mathrm{SO}_{4}, \mathrm{HCl}$, dan $\mathrm{HNO}_{3}$ (Trifosa, 2007). Hidrolisis secara kimiawi memiliki banyak keuntungan, yaitu biaya yang dibutuhkan relatif murah dibandingkan dengan cara enzimatik, sebab harga bahan kimia yang digunakan relatif lebih murah dibandingkan harga enzim. Selain itu, proses hidrolisis dengan cara enzim membutuhkan waktu yang relatif lebih lama dibandingkan cara kimiawi (Novianti, dkk., 2014). Menghidrolisis sampel menggunakan asam klorida yaitu untuk memperoleh monomer pati yaitu glukosa. Menurut (Mastuti \& Setyawardhani, 2010), proses hidrolisis pati yaitu pengubahan molekul pati menjadi monomernya atau unit-unit penyusunnya seperti glukosa. Glukosa yang dihasilkan dari proses hidrolisis selanjutnya difermentasi dengan bantuan ragi roti (Sacharomyces cereviseae) untuk menghasilkan etil alkohol (etanol) dan $\mathrm{CO}_{2}$ melalui reaksi sebagai berikut (Retno \& Nuri, 2011):

$$
\mathrm{C}_{6} \mathrm{H}_{12} \mathrm{O}_{6} \stackrel{\text { Saccharomyces cerevisiae }}{\longrightarrow} 2 \mathrm{C}_{2} \mathrm{H}_{5} \mathrm{OH}+2 \mathrm{CO}_{2}
$$

Fermentasi adalah proses oksidasi yang meliputi perombakan media organik pada mikroorganisme anaerob atau fakultatif anaerob dengan menggunakan senyawa organik sebagai aseptor elektron terakhir. Fermentasi karbohidrat oleh khamir merupakan proses penghasil etanol dan karbondioksida secara anaerob (Sudarmadji, dkk., 1989). Kecepatan fermentasi etanol dipengaruhi oleh beberapa faktor seperti susunan substrat, kecepatan pemakaian zat gizi, tingkat inokulasi, keadaan fisiologis khamir, aktivitas enzim-enzim jalur EMP, toleransi khamir terhadap gula dan alkohol tinggi serta kondisi selama fermentasi (Astuty, 1991).

Penelitian(Nur \& Nuria, 2010) mengukapkan bahwa ubi jalar putih merupakan tanaman pangan yang memiliki kandungan glukosa yang cukup tinggi, berkisar antara 15-20\% setelah dihidrolisa. Kandungan glukosa tersebut memungkinkan untuk dimanfaatkan sebagai bahan baku pembuatan bioetanol melalui proses fermentasi. Proses fermentasi secara anerob pada pH 4-5 dengan menggunakan yeast (Saccharomyces cereviside) sebagai mikroorganisme yang akan menguraikan glukosa menjadi etanol. Agar pertumbuhan dan perkembangbiakan yeast optimal, maka ditambahkan urea sebanyak 4 gram sebagai nutrient ke dalam media. Untuk memisahkan etanol yang terbentuk, dilakukan proses destilasi pada suhu $90-95^{\circ} \mathrm{C}$ selama kurang lebih 3 jam sehingga destilat tidak menetes lagi. Variasi waktu fermentasi yaitu 2, 3, dan 4. Hasil analisis menunjukkan bahwa waktu fermentasi pada hari ke-3 memiliki kadar etanol yang tertinggi yaitu 13,86\% dibandingkan dengan hari-hari lainnya.

\section{Metode \\ Alat dan Bahan}

Peralatan yang digunakan pada penelitian ini adalah neraca analitik, erlenmeyer, gelas kimia, labu ukur, gelas ukur, pipet tetes, corong, penangas listrik, $\mathrm{pH}$ meter, batang pengaduk, aluminium foil, kertas saring, ayakan 40 mesh, magnet stirrer, oven, pompa vakum, blender, spektrometer UV-Vis, seperangkat alat evaporator dan alkoholmeter.

Bahan yang digunakan yaitu ubi jalar kuning, larutan $\mathrm{HCl}$ (Marck), larutan $\mathrm{NaOH}$ (Marck), urea $\left(\left(\mathrm{NH}_{2}\right)_{2} \mathrm{CO}\right)$ (Marck), ammonium sulfat $\left(\left(\mathrm{NH}_{4}\right)_{2} \mathrm{SO}_{4}\right)$ (Marck), ragi roti (saccharomyces cereviseae), reagen anthrone (Marck) dan aquades $\left(\mathrm{H}_{2} \mathrm{O}\right)$.

\section{Prosedur penelitian}

\section{Tahap Pendahuluan}

Ubi jalar dikupas kulitnya kemudian dipotong-potong menjadi bagian-bagian yang lebih kecil, dimbang sebanyak $4 \mathrm{~kg}$, kemudian dicuci hingga bersih dan selanjutnya dikeringkan. Tahap selanjutnya, ubi jalar yang sudah kering dihaluskan menggunakan blender. Kemudian dikeringkan menggunakan oven pada suhu $100^{\circ} \mathrm{C}$ selama 3 jam. Selanjutnya mengayak ubi jalar yang telah dihaluskan dengan menggunakan ayakan 40 mesh.

\section{Tahap hidrolisis}

Sebanyak 10 gram ubi jalar ditimbang dan dimasukkan ke dalam 5 erlenmeyer, ditambahkan larutan $\mathrm{HCl} 21 \%$ sebanyak 100 mL. Selanjutnya, campuran larutan dipanaskan pada suhu $100^{\circ} \mathrm{C}$ selama 2 jam. Kemudian larutan tersebut disaring dengan menggunakan kertas saring, dan dilanjutkan dengan mengukur filtrat yang diperoleh untuk mengethui kadar glukosanya dengan menggunakan spektrometer UV-Vis.

Pengukuran kadar gula dengan menggunakan spektrofotometer UV-Vis dilakukan dengan mengambil $1 \mathrm{~mL}$ sampel hidrolisis kemudian diencerkan menjadi 50 
$\mathrm{mL}$. Dari hasil pengenceran selanjutnya diambil masing-masing $1 \mathrm{~mL}$ kemudian ditambahkan dengan reagen Anthrone sebanyak $5 \mathrm{~mL}$ dan diukur absorbansinya pada panjang gelombang $630 \mathrm{~nm}$. Hasil terbaik yakni yang memiliki kadar gula tertinggi dalam perlakuan ini digunakan untuk perlakuan lebih.

\section{Tahap Fermentasi}

Proses fermentasi dilakukan dengan mengambil filtrat dari hasil hidrolisis dan masing-masing larutan tersebut di masukan ke dalam erlemeyer. Kemudian ditambahkan larutan $\mathrm{NaOH} 6 \mathrm{M}$ hingga $\mathrm{pH}$-nya menjadi 4,5. Selanjutnya, menambahkan 4 gram urea dan 4 gram ammonium sulfat ke dalam masing-masing larutan dan dipasteurisasi pada suhu $80^{\circ} \mathrm{C}$ selama 15 menit lalu didinginkan. Selanjutnya ditambahkan 8 gram ragi roti (Saccharomyces cereviseae). Setelah itu, menutupnya dengan aluminium foil dan dilakukan pendiaman dengan variasi waktu yaitu 3, 4, 5, 6, dan 7 hari pada suhu kamar.

\section{Tahap Pemisahan}

Tahap pemisahan dilakukan dengan memasukan larutan hasil fermentasi ke dalam labu alas bulat dan dipasang pada rangkaian alat evaporator. Pada proses ini dilakukan pemanasan pada suhu $80^{\circ} \mathrm{C}$ untuk memisahkan etanol dari campurannya. Larutan hasil evaporasi selanjutnya ditentukan kadarnya dengan menggunakan alkoholmeter (Osvaldo, dkk., 2012).

\section{Hasil dan Pembahasan}

Hasil penelitian analisis kadar etanol setelah fermentasi dapat dilihat pada Tabel 1 .

Tabel 1 Kadar etanol hasil fermentasi

\begin{tabular}{|c|c|c|c|c|c|}
\hline No. & $\begin{array}{c}\text { Sampel } \\
\text { Ubi Jalar } \\
\text { Kuning } \\
\text { (g) }\end{array}$ & $\begin{array}{c}\text { Sampel } \\
\text { Hasil } \\
\text { Hidrolisis } \\
\text { (mL) }\end{array}$ & $\begin{array}{c}\text { Fermentasi } \\
\text { (Hari) }\end{array}$ & $\begin{array}{c}\text { Alkohol yang } \\
\text { diperoleh } \\
(\mathrm{mL})\end{array}$ & $\begin{array}{c}\text { Kadar } \\
\text { Etanol } \\
(\%)\end{array}$ \\
\hline 1. & 10 & 75 & 3 & 50 & 2,40 \\
\hline 2. & 10 & 75 & 4 & 50 & 7,20 \\
\hline 3. & 10 & 75 & 5 & 50 & 9,70 \\
\hline 4. & 10 & 75 & 6 & 50 & 7,20 \\
\hline 5 & 10 & 75 & 7 & 50 & 7,20 \\
\hline
\end{tabular}

Fermentasi pati ubi jalar menggunakan ragi roti diperoleh kadar etanol sebesar 9,70\% dengan waktu fermentasi selama 5 hari.

Tanaman ubi jalar yang dapat digunakan sebagai bahan bakar alternatif adalah umbinya karena banyak mengandung pati atau karbohidrat sebesar $27,9 \%$ per 100 gram berat bahan. Pati ubi jalar yang dibuat dari umbi ubi jalar (Ipomoea batatas L) merupakan salah satu substrat yang dapat digunakan dalam pembuatan etanol selain substrat bergula dan berselulosa (Judoamidjojo, 1990).

Proses pembuatan bioetanol diawali dengan mengeringkan sampel ubi jalar kuning dengan bantuan sinar matahari yang dilanjutkan dengan proses penghalusan hingga diperoleh sampel ubi jalar halus, yang mana sampel ubi jalar halus tersebut yang akan dihidrolisis. Tahap ini merupakan tahap yang paling penting dalam proses pembuatan bioetanol, karena proses ini menentukan jumlah glukosa yang dihasilkan untuk kemudian dilakukan fermentasi menjadi bioetanol. Menurut Musanif dalam (Assegaf, 2009), prinsip hidrolisis pati adalah pemutusan rantai polimer pati menjadi unit-unit dekstrosa atau monosakarida yaitu glukosa $\left(\mathrm{C}_{6} \mathrm{H}_{12} \mathrm{O}_{6}\right)$.

Glukosa adalah suatu gula monosakharida yang merupakan salah satu karbohidrat terpenting yang digunakan sebagai sumber tenaga bagi manusia, hewan dan tumbuhan. Glukosa dapat dihasilkan melalui hidrolisis polisakarida atau disakarida dan dapat dibuat dari pati-patian (Devita, dkk., 2015).

Proses hidrolisis dapat menggunakan beberapa metode diantaranya yaitu metode kimiawi (hidrolisis asam) dan metode enzimatis (hidrolisis enzim). Metode kimiawi dilakukan dengan cara hidrolisis pati menggunakanasam-asam organik, yang sering digunakan adalah $\mathrm{H}_{2} \mathrm{SO}_{4}, \mathrm{HCl}$, dan $\mathrm{HNO}_{3}$ (Trifosa, 2007). Hidrolisis menggunakan asam klorida yaitu untuk memperoleh monomer pati yaitu glukosa (Minarni, dkk., 2013).

Hasil yang diperoleh dari proses hidrolisis sampel ubi jalar kuning dengan menggunakan asam klorida $21 \%$ adalah 90,857 ppm atau sebesar 4,54\%. Ariyani, dkk., (2013) pembuatan bioetanol dari jerami padi dimana kadar glukosa hasil hidrolisis dianalisis dengan menggunakan spektrometer UV-Vis dengan konsentrasi $\mathrm{HCl}$ yang optimum yaitu pada konsentrasi $\mathrm{HCl} 21 \%$ dengan kadar glukosa yang diperoleh sebesar 70,85 ppm. Groggins dalam (Sukmawati \& Milati, 2009), menyatakan semakin banyak jumlah katalisator yang dipakai makin cepat reaksi hidrolisis terjadi dan dalam waktu tertentu pati yang berubah menjadi glukosa juga meningkat. Hasil hidrolisis tersebut selanjutnya difermentasi.

Proses fermentasi merupakan proses pemecahan karbohidrat dan asam amino secara aerobik, yaitu tanpa memerlukan oksigen. Senyawa yang dapat dipecah 
dalam proses fermentasi terutama adalah karbohidrat, sedangkan asam amino hanya dapat difermentasi oleh beberapa jenis bakteri tertentu (Assegaf, 2009). Prinsip dasar fermentasi adalah mengaktifkan kegiatan mikroba tertentu dengan tujuan mengubah sifat bahan agar dihasilkan suatu yang bermanfaat Perubahan tersebut karena dalam proses fermentasi jumlah mikroba diperbanyak dan digiatkan metabolismenya didalam bahan tersebut dalam batas tertentu (Assegaf, 2009).

Salah satu jenis khamir yang biasa dipakai pada produk alkohol secara fermentasi adalah Saccharomyces cerevisiae (Rahmawati, 2010). Saccharomyces cerevisiae merupakan khamir yang paling penting pada fermentasi utama dan akhir, karena mampu memproduksi alkohol dengan konsentrasi tinggi dan fermentasi spontan (Rahmawati, 2010). Saccharomyces cerevisiae merupakan galur terpilih yang biasa digunakan untuk fermentasi alkohol sebab mempunyai toleransi yang tinggi terhadap alkohol. Saccharomyces cerevisiae dapat memfermentasi sukrosa menjadi etanol pada kondisi netral atau sedikit asam dalam kondisi anaerob, pada kondisi ini $10 \%$ glukosa dapat direspirasi menjadi $\mathrm{CO}_{2}$ dan menghasilkan kadar etanol kurang dari 50\% (Hawab, 2004).

Sebelum difermentasi $\mathrm{pH}$ larutan sampel perlu dinetralkan menjadi $\mathrm{pH}$ 4,5. Keasaman atau $\mathrm{pH}$ medium merupakan salah satu faktor penting yang mempengaruhi pertumbuhan mikroorganisme dan pembentukan produk dalam proses fermentasi karena setiap mikroorganisme mempunyai kisaran $\mathrm{pH}$ optimal (Idral, dkk., 2012). Hal ini sesuai dengan pendapat Roukas dalam (Azizah, dkk., 2012) bahwa kisaran pertumbuhan mikroba Saccharomyces cerevisiae yaitu $\mathrm{pH}$ 3,5-6,5 dan pada $\mathrm{pH} 4,5$ adalah kondisi $\mathrm{pH}$ yang maksimal dapat dicapai. (Fadel, 2000) mengungkapkan bahwa produksi etanol yang optimum diperoleh dengan penggunaan $\mathrm{pH}$ awal 4.06.0. (Graves, dkk., 2006) telah melakukan penelitian bahwa tidak ada produksi etanol dibawah $\mathrm{pH}$ 4.0, dikarenakan pada $\mathrm{pH}$ tersebut mikroba tidak dapat tumbuh, sedangkan pada pH 6.0 adalah jumlah maksimum untuk kedua-duanya. Sementara (Osman, dkk., 2011) juga menyatakan hal yang sama, bahwa laju pertumbuhan mikroba diperoleh pada $\mathrm{pH} 5.5$ dan merupakan medium untuk produksi etanol. Sedangkan (Rivera, dkk., 2006) mempertimbangkan bahwa temperatur sebagai variabel untuk mengevaluasi jumlah maksimum yang diharapkan sebagai parameter dari proses fermentasi. Berdasarkan penelitian yang dilakukan, produksi etanol yang maksimum dapta dicapai pada temperatur 28$31^{\circ} \mathrm{C}$. Penelitian (Duhan, dkk., 2013) puncak produksi alkohol dicapai pada suhu $35^{\circ} \mathrm{C}$ dan mikroba akan tumbuh optimal pada kisaran temperatur $30-35^{\circ} \mathrm{C}$. Hal ini menunjukan bahwa apabila pada suhu yang terlalu rendah, maka proses fermentasi akan berlangsung secara lambat. Sedangkan pada suhu yang terlalu tinggi menyebabkan mikroba Saccharomyces cerevisiae akan mati sehingga proses fermentasi tidak dapat berlangsung. Selain $\mathrm{pH}$ dan suhu, pemberian nutrisi juga mempegaruhi tumbuhnya Saccharomyces cerevisiae. Penelitian ini menggunakan ragi Saccharomyces cerevisiae karena mikroba Saccharomyces cerevisiae dapat menghasilkan alkohol hingga 2\% dalam 72 jam (O’Leary, dkk., 2004).

Proses fermentasi pada penelitian ini dilakukan selama 5 hari. Hasil fermentasi ubi jalar selanjutnya dievaporasi untuk memisahkan etanol dari campurannya pada suhu $80^{\circ} \mathrm{C}$. Pada proses evaporasi senyawa yang menguap terlebih dahulu adalah etanol karena memiliki titik didih yang rendah yaitu $78,3^{\circ} \mathrm{C}$, dibandingkan dengan pelarutnya seperti air yang memiliki titik didih $100^{\circ} \mathrm{C}$ (Ariyani, dkk., 2013). Hasil Evaporasi kemudian dilakukan pengukuran kadar etanolnya dengan menggunakan alkohol meter. Hasil pengukuran kadar etanol dari 50 $\mathrm{mL}$ alkohol dalam rentang waktu fermentasi selama 5 hari dengan kadar gula reduksi 4,54\% diperoleh kadar etanol sebesar 9,70\%.

\section{Kesimpulan}

Kadar etanol ubi jalar kuning yang difermentasi menggunakan ragi roti (Saccharomyces cerevisiae) dengan alkohol 50 mL adalah 9,70\%.

\section{Ucapan Terima Kasih}

Penulis mengucapkan terimakasih kepada kepala laboran Program Studi Pendidikan Kimia dan semua pihak yang telah membantu dalam pelaksanaan penelitian ini.

\section{Referensi}

Ariyani, E., Kusumo, E., \& Supartono. (2013). Produksi bioetanol dari jerami padi (oryza sativa 1). Jurnal Institut Teknologi Nasional, 2(2), $168-172$.

Assegaf, F. (2009). Prospek produksi bioetanol bonggol pisang (musa paradisiacal) menggunakan metode hidrolisis asam dan enzimatis. Karya Tulis Daya Saing 
Keunggulan dan Penguasaan IPTEKS (Ilmu Pengetahuan Teknologi dan Seni. Dso Purwokerto, Universitas Jenderal Soedirman Rso Semarang.

Astuty, E. D. (1991). Fermentasi alkohol kulit buah pisang (Musa sapientum Lamb) dengan berbagai jenis inokulum. Tesis, Universitas Gadjah Mada, Yogyakarta.Tidak diterbitkan.

Azizah, N., Al-Baarri, A. N., \& Mulyani, S. (2012). Pengaruh lama fermentasi terhadap kadar alkohol, ph, dan produksi gas pada proses fermentasi bioetanol dari whey dengan substitusi kulit nanas. Jurnal Aplikasi Teknologi Pangan, 1(2), 72-77.

Damardjati, D. S., \& Widowati. (1994). Pemanfaatan ubi jalar dalam program diversifikasi guna mensukseskan swasenbada pangan. Balai Penelitian Tanaman Pangan, 3(2), 1-25.

Demirbas, A. (2005). Bioethanol from cellulosic material: A renewable motor fuel from biomass. Energy Source, 27, 327-337.

Devita, C., Pratjojo, W., \& Sedyawati, R. M. S. (2015). Perbandingan metode hidrolisis enzim dan asam dalam pembuatan sirup glukosa ubi jalar ungu. Indonesian Journal of Chemical Science, 4(1), 15-19.

Duhan, J., A, K., \& Tanwar, S. (2013). Bioethanol production from starchy part of tuberous plant (potato) using saccharomyces cerevisiae mtcc-170 Afri. J. Microbiol, $7(46), 5253-5260$.

Fadel, M. (2000). Alcohol production from potato industry starchy waste. Egyp. J. Microbiol, 35(3), 273-287.

Graves, T., Narendranath, N., K, D., \& Power, R. (2006). Effect of ph and lactic or acetic acid on ethanol productivity by saccharomyces cerevisiae in corn mash. J. Indust. Microbiol. Biotechnol, 33, 469-474.

Hawab. (2004). Pengantar biokimia. Erlangga: Jakarta.

Idral, D. D., Salim, M., \& Mardiah. (2012). Pembuatan bioetanol dari ampas sagu dengan proses hidrolisis asam dan menggunakan saccharomyces cerevisiae. Jurnal Kimia Unand, 1(1), 34-39.

Judoamidjojo, M. (1990). Teknologi fermentasi. IPB-Press: Bogor.

Kartika, B., Sutanti, R., \& Nuzulis, A. (1992). Petunjuk evaluasi produk industri hasil pertanian. PAU Pangan dan Gizi UGM: Yogyakarta.

Mastuti, E., \& Setyawardhani, A. D. (2010). Pengaruh variasi temperatur dan konsentrasi katalis pada kinetika reaksi hidrolisis tepung kulit ketela pohon. Ekuilibrium, 9(1), 2327.

Minarni, N., Ismuyanto, B., \& Sutrisno. (2013). Pembuatan bioetanol dengan bantuan saccharomyces cerevisiae dari glukosa hasil hidrolisis biji durian (durio zhibetinus. Kimia Student Journal, 1(1), 3642.

Mulyono, A. M. W., Handayani, C. B., Tari, A. I. N., \& Zuprizal. (2011). Fermentasi etanol dari jerami padi. Karya Tulis Ilmiah. Lembaga Penelitian dan Pengabdian Kepada Masyarakat Universitas Veteran Bangun Nusantara Sukoharjo.

Novianti, H., Supartono, \& Siadi, K. (2014). Pengolahan limbah serbuk gergaji kayu sengon laut menjadi bioetanol menggunakan saccharomyces cerevisiae. Indonesian Journal of Chemical Science, 3(2), 147-151.

Nur, \& Nuria. (2010). Pebuatan bioetanol dari ubi jalaar putih (ipomea batatas linneaaus). Skripsi Jurusan Kimia, Universitas Sebelas Maret Surakarta, Fakultas Teknik, Program Studi Diploma III Teknik Kimia: Tidak diterbitkan.

O'Leary, V. S., Green, R., Sullivan, B. C., \& Holsinger, V. H. (2004). Alcohol production by selected yeast strains in lactase hydrolyzed acid whey. Jurnal Biotecnology and Bioengineering, 19(7), 1019-1035.

Osman, M., Khattab, O., Hammad, I., \& El-Hussieny, N. (2011). Optimization of biofuel production by saccharomyces cerevisiae isolated from sugar cane bagasse. 
J. Am. Sci, 7(5), 485-492.

Osvaldo, Z. S., Panca, P. S., \& aisal, M. (2012). Pengaruh konsentrasi asam dan waktu pada proses hidrolisis dan fermentasi pembuatan bioetanol dari alang-alang. Jurnal Teknik Kimia, 2(18), 52-62.

Rahmawati, A. (2010). Pemanfaatan limbah kulit ubi kayu (manihot utilissima pobl.) dan kulit nanas (ananas comosus l.) pada produksi bioetanol menggunakan aspergillus niger. (Skripsi Jurusan Biologi), Universitas Sebelas Maret Surakarta, Fakultas Matematika dan Ilmu Pengetahuan Alam: Tidak diterbitkan.

Retno, T. D., \& Nuri, W. (2011). Pembuatan bioetanol dari kulit pisang. Prosiding Seminar Nasional Teknik Kimia Kejuangan.

Rikana, H., \& Adam, R. ( 2008). Pembuatan bioethanol dari singkong secara fermentasi menggunakan ragi tape. Laporan Penelitian Jurusan Teknik Kimia Fakultas Teknik Universitas Diponegoro. Semarang.

Rivera, E., Costa, A., Atala, D., Maugeri, F.,
Maciel, M., \& FR, M. (2006). evaluation of optimisation techniques for parameter estimation: Application to ethanol fermentation considering the effect of temperature. J. Process Biochem, 41, 16821687.

Sudarmadji, S., Kasmidjo, R., Sardjono, Wibowo, D., Margino, S., \& Rahayu, E. S. (1989). Mikrobiologi pangan. UGM Yogyakarta.

Sukmawati, R. F., \& Milati, S. (2009). Pembuatan bioetanol dari kulit singkong. Program Studi Diploma III Teknik Kimia, Fakultas Teknik. Universitas Sebelas Maret Surakarta.

Trifosa, D. (2007). Konversi Pati Jagung Menjadi Bioetanol Skripsi Program Studi Kimia, FMIPA ITB, Bandung: tidak diterbitkan

Zuraida, N., \& Supriati, Y. (2001). Usahatani ubi jalar sebagai bahan pangan alternatif dan diversifikasi sumber karbohidrat. Buletin agrobio vol 4 no 1 Balai Penelitian Bioteknologi Tanaman Pangan. Bogor. 